\title{
Use of SAR in regional methane exchange studies
}

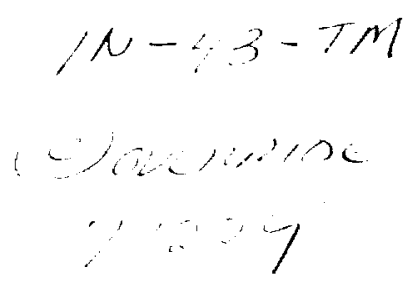

\author{
L. A. MORRISSEY, G. P. LIVINGSTON \\ NASA Ames Research Center, MS 242-4, Moffett Field, CA 94035-1000, USA
}

and S. L. DURDEN

Jet Propulsion Laboratory, California Institute of Technology, 4800 Oak

Grove Drive, Pasadena, CA 91109, USA

(Received 20 April 1993; in final form 10 December 1993)

\begin{abstract}
Significant sources of uncertainty in global trace gas budgets are due to lack of knowledge concerning the areal and temporal extent of source and sink areas. Synthetic aperture radar (SAR) is particularly suited to studies of northern ecosystems because of its all-weather operating capability which enables the acquisition of seasonal data. As key controls on methane exchange, the ability to differentiate major vegetation communities, inundation, and leaf area index (LAI) with satellite and airborne SAR data would increase the accuracy and precision of regional and seasonal estimates of methane exchange. The utility of SAR data for monitoring key controls on methane emissions from Arctic and boreal ecosystems is examined.
\end{abstract}

\section{Introduction}

Global trace gas budgets are dependent upon knowledge of the rate of gas exchange across the surface-atmosphere interface, as well as, the areal and temporal extent over which the specific exchange rates are representative. Although various international efforts have been committed to improving our understanding of exchange rates, efforts to characterize the areal and temporal distribution of trace gas sources and sinks have lagged considerably and now represent the largest uncertainty in current understanding of many trace gas global budgets (Bartlett and Harriss 1993).

Airborne and satellite-based synthetic aperture radar (SAR) offer unique capabilities for the study of dynamic processes related to biogenic trace gas emissions in wetland environments, providing information on the spatial distribution and type of wetlands and on the temporal distribution of inundation. The capability of microwaves to penetrate cloud cover and to detect standing water beneath vegetation canopies has been demonstrated (Hess et al. 1990). Theoretical models and empirical studies have also demonstrated the sensitivity of radar backscatter to changes in leaf area index (LAI) and biomass in well-drained grasslands, agricultural communities (Ulaby ef al. 1984; Wu 1987), and non-woody wetland communities (Cihlar et al. 1992; Ott et al. 1990). Moreover, as these factors are also directly related to the functioning of the underlying microbial communities (aerobic vs. anaerobic) and dominant surface-atmosphere gas exchange processes (molecular diffusion vs. plantmediated transport), we examined the potential of using ERS-I SAR and aircraft 
AIRSAR to map community type, green leaf area and inundation as they relate to surface-atmosphere trace gas exchange in boreal and Arctic ecosystems.

Although Arctic and boreal ecosystems are believed to contribute between 4 and 16 per cent of the annual atmospheric methane $\left(\mathrm{CH}_{4}\right)$ burden (Aselmann and Crutzen 1989; Fung et al. 1991), considerable uncertainty exists in current understanding of the global methane budget (Matthews and Fung 1987). This understanding depends on the net balance defined by the exchange rates and the areal and temporal representation of the methane source and sink areas. SAR offers potential to assess the spatial and temporal distributions of environmental controls as they relate to methane emissions in these northern ecosystems.

\section{Environmental controls on methane exchange}

Numerous studies have contributed to our current understanding of factors and processes regulating methane exchange in northern wetlands. In brief, the rate of methane emissions is defined by those factors which influence its production and oxidation in the soil profile and its release into the atmosphere (Aselmann and Crutzen 1989; Conrad 1989). The presence or absence of inundation largely determines oxygen availability in the underlying soils and thus whether microbial decomposition of organic materials proceeds via reductive (anacrobic) or oxidative (aerobic) pathways to yield $\mathrm{CH}_{4}$ or $\mathrm{CO}_{2}$, respectively. Oxygen in the soil profile has a significant effect on the rate of methane emissions. not only inhibiting methanogenesis but also in supporting methane-oxidizing microbial communities. Therefore, variation in local to regional scale hydrology substantially influences both the suite of biogenic gases exchanged across the surface-atmosphere interface and their exchange rates at any given time and season.

Various adaptations by herbaceous wetland vegetation to enhance the transport of oxygen from the atmosphere into the root zone to support root respiration are also known to enhance the transport of reduced gases, such as methane. concentrated in the substrate directly to the atmosphere (Conrad 1989). These wetland communities thus serve both as an organic source ultimately subject to microbial decomposition and as an effective transport pathway which largely bypasses potential oxidation at the surface. Plant-mediated transport of methane characteristically dominates the total exchange within northern wetlands (Morrissey and Livingston 1992; Bartlett et al. 1992). Furthermore, the magnitude of plant-mediated emissions corresponds directly with the green LAI in northern ecosystems (Morrissey and Livingston 1992).

\section{Site description}

The study areas represent both Arctic (non-forested) tundra and subarctic (forested) taiga ecosystems in Alaska. The tundra study area at Barrow, located within the Arctic Coastal Plain of the North Slope of Alaska, represents an extensive, poorly drained lowland with thousands of lakes and ponds overlying permanently frozen ground. The vegetation is dominated by herbaceous sedges and grasses (fens) with scattered shrubs on the more well drained soils. The taiga study area, located in and around Fairbanks and Minto Flats in central Alaska, represents a complex mosaic of coniferous and deciduous forests in the uplands and herbaceous fens, forested and shrub hogs, and water bodies in the lowlands. 


\section{Methods}

Methane exchange rates, community vegetation type, green leaf area, and water table position were measured in situ as part of current efforts to predict regionalseasonal methane flux from northern ecosystems. Methane flux measurements were made in the summer of 1987,1988 , and 1991 using enclosed chambers on a floating collar deployed over a 20 minute period. At each site, water table levels $(z)$ were measured at 10 random points along a $100 \mathrm{~m}$ transect as being below $(z \leq-5 \mathrm{~cm})$, at $(-5<z \leq 0 \mathrm{~cm})$, or above $(z>0 \mathrm{~cm})$ the surface. Additionally, at herbaceous, inundated sites $(n=10)$, the vegetation was clipped at water level at five random points along the transect. The single-sided green leaf area of the clipped samples was measured in the laboratory using a LICOR 3100 area meter. Measured leaf areas were subsequently normalized for the ground surface area sampled, yielding a leaf area index which could be compared with SAR backscatter observations. Tundra sites were selected to represent a range of LAI and inundation levels along the Barrow access road. Taiga sites were selected based on a stratified sample by vegetation community and accessibility by vehicle, boat, helicopter, or float plane. Methane flux measurements (123) were made at the taiga sites in 1988 and 1991.

ERS-1 SAR satellite data acquired on 18 August 1991 over Barrow, Alaska were analyzed to differentiate water table levels and LAI, concurrent with field data collection. Backscatter observations to test for dependence on green leaf area and water table position were based on a spatial average of 5 by 5 pixels. AIRSAR data acquired with the NASA DC-8 aircraft on 6 May 1991 over Fairbanks were utilized to distinguish dominant vegetative communities as they relate to methane emissions. Data from several hundred four-look pixels were averaged together to calculate the mean scattering characteristics for each vegetation class.

\section{Results}

Methane emissions and ERS-1 SAR backscatter were related positively to water table position in the Arctic tundra (figure 1). Rates of methane emissions were

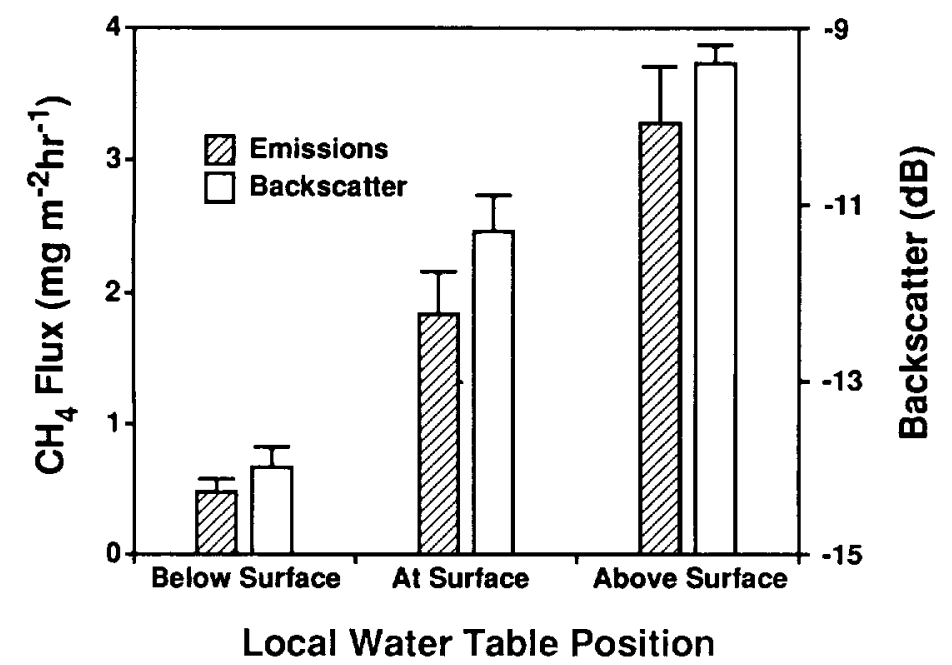

Figure 1. Methane flux and ERS-I SAR backscalter related to the position of the local water table in herbaceous Arctic tundra $(n=21)$, mean values \pm standard error. 
greatest for inundated sites, decreasing dramatically for comparable sites where the water table is either at, or below the surface (Morrissey and Livingston 1992). Similarly, backscatter for ERS-1 C-band SAR satellite data was directly related to the position of the local water table with the strongest return from herbaceous sites in standing water. The enhanced backscatter from these sites was likely due to double bounce scattering between vegetation and standing water, although this cannot be confirmed until multipolarized data are available. Figure 2 demonstrates the dependence of ERS-1 SAR backscatter on green leaf area for the tundra sites. Since methane flux also is proportional to LAI, estimation of LAI using ERS-1 SAR could improve regional estimates of trace gas exchange.

The successful discrimination of boreal communities using AIRSAR multiband, quad-polarized SAR data as they relate to mid-season methane exchange rates is demonstrated in figure 3. C-VV backscatter (ERS-1 SAR configuration) for methane consuming upland forest and tall shrub communities were well separated from backscatter from bogs and open water source areas. Methane-producing communities include herbaceous, inundated fens representing high rates of methane emissions, while more well drained bogs or black spruce forested wetlands characteristically have low rates of exchange. Methane was removed from the atmosphere by soil methanotrophic communities in well drained upland deciduous and coniferous forests. In contrast to the enhanced return from inundated, vegetated sites (figure 1), radar backscatter from open water sites was characteristically low (figure 3). Overall classification accuracy for these boreal communities using a AIRSAR data was 89 per cent, with individual class accuracies varying from a low of 67 per cent for riparian tall shrubs to 100 per cent for coniferous forest, flooded, bare soil, and open water classes (Durden et al. submitted). Backscatter from open water sites was characteristically low due to specular scattering while low return from bogs was due to diffuse scattering of the radar off an irregular ground surface resulting in little return to the sensor. Fens, although a large methane source, had not yet developed at the time of the AIRSAR overflight. Results from the Arctic tundra, however, suggest that discrimination of these herbaceous and typically inundated wetlands will be possible because of strong double bounce scattering as shown in figures 1 and 2. Because taiga LAI values are

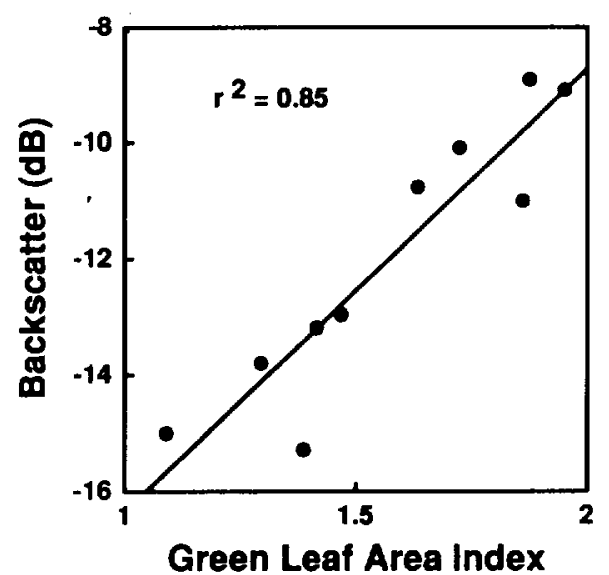

Figure 2. Relationship between green LAI above water and ERS-1 SAR observations for Arctic tundra sites. 


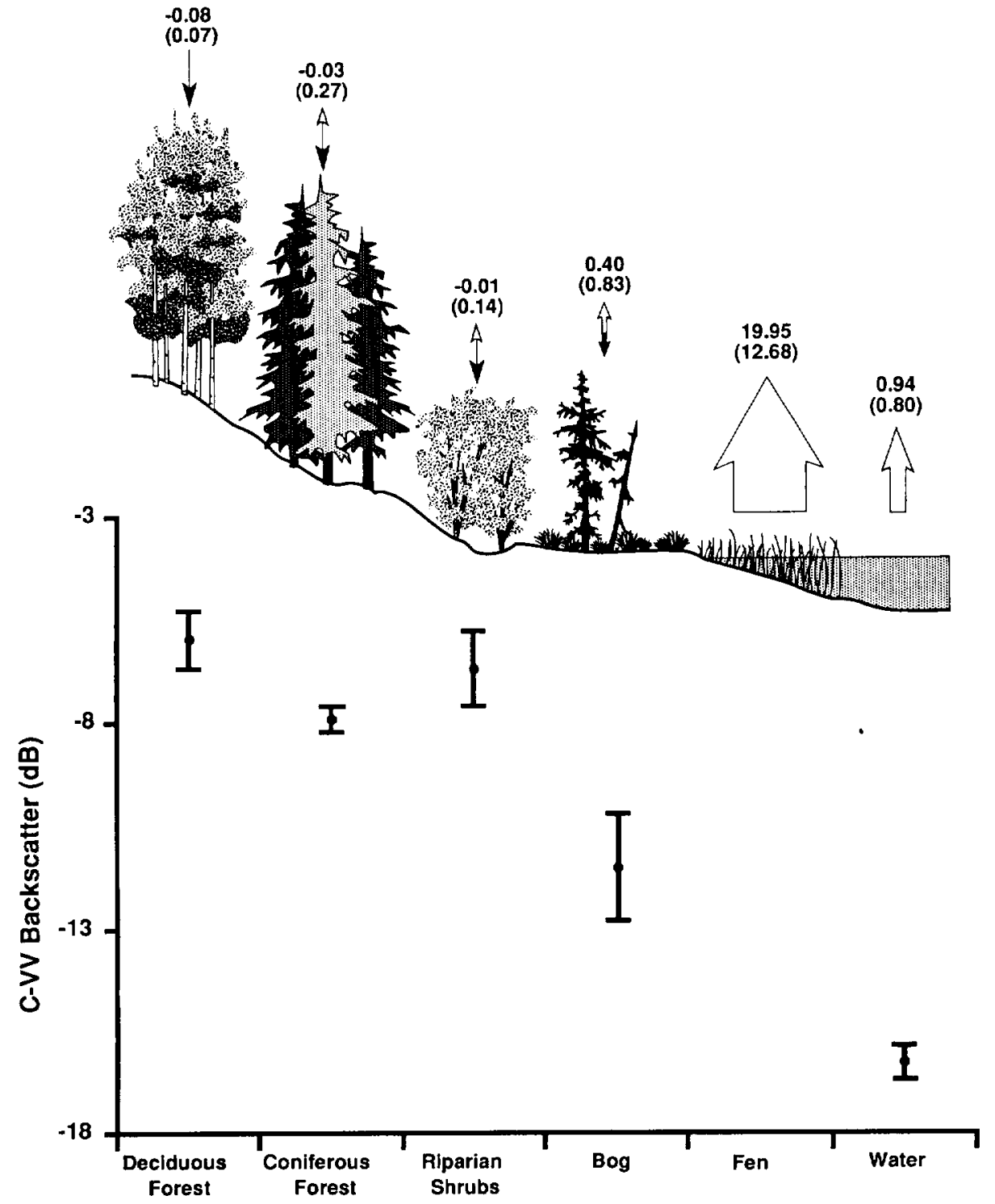

Figure 3. Methane flux ( $\mathrm{mg} \mathrm{CH}_{4} \mathrm{~m}^{-2} \mathrm{hr}^{-1}$ ) and AIRSAR C-VV backscatter from taiga vegetation communities along an idealized elevation gradient; mean values \pm standard deviation. Classes with number of observations (from left to right) represent deciduous forest (11), coniferous forest (8), riparian tall shrubs (12), bogs (22), fens (56), and open water (14)

often 2-5 fold greater than tundra LAI values, we expect a stronger radar return from taiga than from tundra herbaceous sites, however, the relationship is dependent on whether the C-band radar signal will penetrate these dense canopies.

\section{Summary}

We have demonstrated the use of SAR in mapping key environmental factors related to methane exchange rates in northern ecosystems. SAR data are well suited 
for characterizing the type and areal extent of vegetation communities, as well as, quantifying the seasonal and interannual extent and periodicity of inundation regardless of cloud cover. The capability to monitor LAI in inundated herbaceous tundra with SAR is suggested, although evaluation over a wider range of LAI values is required to demonstrate this capability in taiga wetlands. The availability of vegetation communtiy type and the extent of timing of inundation alone would greatly add to current capabilities to understand carbon exchange in northern ecosystems and to predict their response to past or anticipated climate change. Regional estimates of surface-atmosphere methane exchange would be further strengthened by SAR-derived estimates of LAI and water table level throughout the growing season for methane source areas (herbaceous fens). Incorporation of SAR into ongoing measurement and modelling activities offer substantial potential for improving our understanding of wetland exchange processes at a global scale.

\section{Acknowledgments}

This research was supported by the National Aeronautics and Space Administration's Polar and Interdisciplinary Research in Earth Science Programs.

\section{References}

Asilmans. I. and Crutzin. P. J., 1989, Global distribution of natural freshwater wetlands and rice paddies. their net primary productivity, seasonality, and possible methane emissions. Joumal of Amospheric Chemistry, 8, 307-358.

Bartlitt, K. B.. Crill. P. M.. Sass, R. L., Harriss, R. C., and Disf, N. B., 1992, Methane emissions from tundra environments in the Yukon-Kuskokwim Delta, Alaska. Journal of Geophysical Research, 97, 16645-16660.

Baktlitt, K. B., and HaRkiss, R. C., 1993, Review and assessment of methane emissions from wetlands. Chemosphere, 26, 261-320.

Chilar, J., Pultz, T. J., and Gray, A. L., 1992, Change detection with synthetic aperture radar. International Journal of Remote Sensing 13,401-414.

Conral, R., 1989. Control of methanc production in terrestrial ecosystems. In Exchange of Trace Gases hetween Terrestrial Ecosystems and the Atmosphere, edited by M. A. Andreate and D. S. Schimel (New York: John Wiley), pp. 3958.

Durden, S. L.. Morrissi:y, L. A., and Livingston, G. P., Polarimetric radar classification of boreal communities for trace gas studies. Remote Sensing of Envirmment, submitted.

Fung, I., John, J., Lierner, J., Matthews, E., Prathi:r, M., Stilili, P. L., and Frasir. P. J., 1991. Three-dimensional model synthesis of the global methane cycle. Journal of Geophysical Re'se'arch, 96, 1303313065.

Hess, L. L., Mis.ack, J. M., and SimonitT. D. S., 1990, Radar detection of flooding bencath the forest canopy: a review. International Journal of Remote Sensing. 11, 13131325.

Matmifws E.. and Fung, I., 1987. Methane emission from natural wetlands: global distribution, area and environmental characteristics of sources. Global Biogeochemical Cycles, 1, 61 86.

Morrissty, L. A., and Livingiston, G. P., 1992, Methane emissions from Alaska Arctic tundra: an assessment of local spatial variability. Journal of Geophysical Research, 97D, 1666116670.

Ott, J. S., Kasischke, E. S., Frinch, N. H., Gross, M. F., and K1.jmas, V., 1990, Evaluation of multichannel SAR data for analysis of a mid-Atlantic coastal wetland ecosystem. Proceedings of International Geoscience and Remote Sensing Simposium IGARSS 90. held in College Park, Maryland on 2024 May 1990 (New York: Institute of Electrical and Electronics Engineers) Proc. IGARSS 90, pp. 453 456.

Ulaby, F. T.. Alliln, C. T. Egili, G., and Kanfmasu, E., 1984, Relating the microwave backscattering coefficient to leal area index. Remote Sonsing of Finironment, 14, 113-133.

WU, S. T., 1987. Preliminary report on measurements of forest canopies with $\mathrm{C}$ band radar scatterometer at NASA NSTL. I.E.E.E. Transactions in Geoscience and Remote Sensing, 24, 403409. 